\title{
Tumor Findings Reference Identifier
}

National Cancer Institute

\section{Source}

National Cancer Institute. Tumor Findings Reference Identifier. NCI Thesaurus. Code C119936.

A sequence of characters used to identify, name, or characterize the tumor findings reference. 